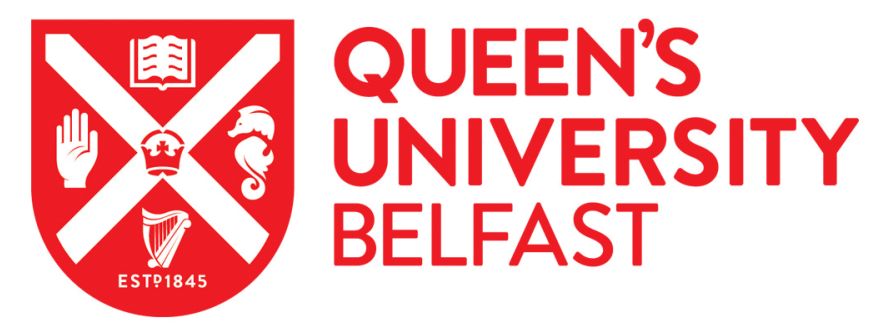

\title{
Residential child care workers and relationship based practice in a culture of fear
}

Brown, T., Winter, K., \& Carr, N. (2018). Residential child care workers and relationship based practice in a culture of fear. Child and Family Social Work, 23, 657-665. https://doi.org/10.1111/cfs.12461

\author{
Published in: \\ Child and Family Social Work
}

\section{Document Version:}

Peer reviewed version

Queen's University Belfast - Research Portal:

Link to publication record in Queen's University Belfast Research Portal

\section{Publisher rights}

Copyright 2018 Wiley. This work is made available online in accordance with the publisher's policies. Please refer to any applicable terms of use of the publisher.

\section{General rights}

Copyright for the publications made accessible via the Queen's University Belfast Research Portal is retained by the author(s) and / or other copyright owners and it is a condition of accessing these publications that users recognise and abide by the legal requirements associated with these rights.

Take down policy

The Research Portal is Queen's institutional repository that provides access to Queen's research output. Every effort has been made to ensure that content in the Research Portal does not infringe any person's rights, or applicable UK laws. If you discover content in the Research Portal that you believe breaches copyright or violates any law, please contact openaccess@qub.ac.uk. 


\section{Residential child care workers: relationship based practice in a culture of fear}

\section{Abstract}

In a contemporary context dominated by reports of the historical institutional abuse of children and young people in residential children's homes, and where the voice of workers is largely absent, this study explores the views and experiences of 26 workers in the Republic of Ireland regarding relationship-based practice. Using an exploratory, qualitative approach and informed by 'appreciative inquiry'; semi-structured interviews were undertaken with 26 residential care workers. The findings highlight that relationship-based practice has not been fully understood and/or embraced in practice because of a culture of fear that has permeated the Irish residential childcare system. Using theoretical concepts associated with the sociology of fear, the paper explores their effects on practice and argues that these are amplified given the current low status of residential care workers, the impact of media reports and the influence of current discourses around professional practice in which 'objective' and 'emotionally detached' practice is viewed as synonymous with efficiency and effectiveness. The paper ends by considering implications for professional practice in residential childcare settings. 


\section{Residential child care in Ireland}

Reflecting developments in 'out of home care' nationally and internationally (Whittaker et al., 2015), the residential child care sector in the Republic of Ireland has been (and remains) a contested space in terms of its purpose, role and function with changes both reflecting and being shaped by the broader social, cultural and political context (Gilligan, 2009; Fenton, 2015). Defined as 'a physical setting in which children and young people are offered care: physical nurturing; social learning opportunities; the promotion of health and wellbeing and specialized behaviour training' (Fulcher, 2001, p. 418); residential child care in the Republic of Ireland currently caters for about $5 \%$ of the total population in care. It is well documented (Raftery and O' Sullivan, 1999; Gilligan, 2009) that, historically in the Republic of Ireland, the role of the Church was pivotal with religious orders being largely left to their own devices in the delivery of institutional care to children. Underpinning discourses that shaped provision at the time namely: rescuing children and young people from 'deprivation' and/or 'depravity'; restoring their physical, moral and spiritual wellbeing; and reintegrating them as fully functioning individuals into their families, communities and society; are reflective of this (Gilligan, 2009; Whittaker et al., 2015).

The previously, rarely explored, workings of residential child care became the subject of increasing scrutiny from the 1980's onwards where, in the Republic of Ireland, the sector has come under sustained criticism following revelations of systemic abuse experienced by former residents whilst in the care of institutions run by religious orders. In the 1990's, in response to former residents' legal actions, the Irish government passed the Commission to Inquire into Child Abuse Act (2000). The Commission, commonly known as the Ryan 
Commission, had four functions namely to: investigate allegations of abuse; listen to victims; consider the governance, management and working practices of residential institutions; and to consider impact on individuals by their experiences. The Commission dealt with claims of abuse in any residential institution in Ireland from 1914 onwards. The report, known as the Ryan Report, was published in 2009 and contained over 1,000 individual accounts of former residents regarding their experiences of physical and emotional abuse, neglect and sexual abuse. A series of reforms has since followed focused on: updating residential child care policy and legislation; making more effective and transparent the delivery, regulation and management of the sector; and strengthening the voice of the child. The publication of annual implementation review reports indicate that reforms are well underway. Despite this, the residential child care sector remains under the public gaze. At the time of writing, the discovery of the remains of hundreds of babies and young children in an unmarked and unregistered site at Tuam residential mother and baby home in County Galway (Guardian newspaper, 2017) raises concerns about historical attitudes towards and the treatment of this group of children whose deaths were recorded but who were not afforded a proper burial and whose identity was therefore not honoured.

In a contemporary residential child care context a new set of discourses are shaping the sector including: regulation; value for money; risk aversion and evidence of outcomes for children. Increased regulation is identifiable through the growing reliance by residential child care workers on processes, procedures that aim to enhance the 'professional' elements of their role (Smith, 2009). Sitting alongside this, the increased attention towards outcomes, reflected in the growing interest in interventions and effective models of therapeutic and relationship based models of care (Berridge et al., 2011; MacDonald et al., 2012; Whittaker et al., 2015; 
Cahill et al., 2016), demands enhanced 'caring' capacities of residential child care workers including emotional and physical proximity. Given the relentless negative publicity regarding residential child care, the requirement for more meaningful relationships between workers and children is challenging (Smith, 2009).

\section{Risk aversion, relationships and residential child care practice}

The significance of meaningful relationships for young people in residential child care has been acknowledged (Gallagher and Green, 2012; MacDonald et al., 2012; Harder et al., 2013; Soenen et al., 2013) in terms of: promoting resilience (Whittaker et al., 2015); supporting young person with challenging behaviour (MacDonald et al., 2012); ensuring active participation in decisions affecting young people (Cahill et al., 2016); and as pre-conditions for effective interventions (Berridge et al., 2011). Relationship based practice has at is core an emphasis on the: centrality of relationship; reciprocity in adult/child relationships; and social, emotional and physical intimacy (Ruch, 2010). Elements of this approach define some of the therapeutic models that underpin the delivery of residential child care (Berridge et al., 2011; MacDonald et al., 2012; Anglin, 2014) and yet, except for this and recent research by Cahill et al. (2016), there has been a dearth of research that focuses on the experiences and views of residential child care staff regarding relationships and relationship based practice.

One contributory factor is that whilst relationship based practice is promoted (Cahill et al., 2016), it exists in a context shaped by risk aversion. The concept of risk adverse practice is not new (Kemshall, 2002). Essentially characterised by 'the avoidance of harms rather than the pursuit of the collective good' (Kemshall, 2002, p.22), evidence of its pervasive nature in social work can be seen in the rise in bureaucratic processes and procedures for identifying 
and managing risk with the aim of reducing or avoiding risk. While, on the one hand, it makes sense for residential child care workers to identify and ensure that children are spared exposure to unnecessary and/or harmful risks; a reliance on risk averse processes and procedures can encourage a cautious, if not inflexible, defensive approach and a reluctance to engage in creative and intuitive practice (Kemshall, 2002; Smith, 2009). Inevitably, in the context of residential child care, this impacts on daily practice. Smith $(2009$, p. 4), for example argues that:

The terminology of risk, epitomised in the refrain that will be so common to social workers or residential workers, 'have you done a risk assessment?', is symptomatic of this collective, essentially fearful state of mind, and can only be made sense of within these wider social trends and attitudes towards risk.'

\section{Fear, relationship based practice and residential child care practice}

The notion that, within a risk averse context, residential child care workers daily practice might be influenced by a 'fearful state of mind', provides a key focus of this paper that explores the concept of fear and how it might be applied to understand everyday residential child care practice. With regards to the concept of fear, the work of Furedi $(2005,2006)$ and Furedi and Bristow (2008), is perhaps the best known. His work, which builds on the work of Beck (1992), argues that a pre-occupation with risk shapes interpersonal behaviour through a prevailing 'culture of fear'. Furedi (2006) identified three principle features of the culture of fear: first, as a shift in moral reaction to harm where harm is individualised and viewed as an outcome of irresponsible behaviour; second, a changing narrative of harm, where responses are likely to be shaped not so much by the disaster itself, as by the public attitudes that prevail in society; and third, the evaluation of everything from the perspective of safety is a defining 
characteristic of modern society again with the same result. Understood in relation to residential child care, Smith (2009, p.15) argues that fear in workers is engendered through policies and procedures that attempt to 'impose certainty and order on acts and relationships that are irredeemably uncertain and ambiguous [and where] there are consequences for the slightest breach'. In daily residential child care practice this can result in workers' 'fear of touching' young people, of 'emotional intimacy' with them and reluctance to confront challenging behaviour through a fear of allegations being made against them (Smith, 2009, p. $95,49)$.

These aspects of practice are at odds with the increased emphasis on therapeutic and relationship based models of residential child care (MacDonald et al., 2012; Whittaker et al., 2015; Author's own, unpublished, 2017) and where there is an emphasis on: social, physical and emotional intimacy (Berridge et al., 2011); the importance of the internal and external worlds of both the professional and the young person as a means of gaining information, insight (Ruch, 2010); the dignity, worth, value of the individual child; and the centrality of the child/keyworker relationship (MacDonald et al., 2012). In understanding how fear pervades the practice of residential child care workers, an applied framework that operationalises Furedi's broad concepts is required. For that reason, this paper draws on the work of Tudor (2003) regarding the sociology of fear. Tudor's model depicts the relationship between structure (macro factors) and individual agency (micro factors) in shaping the experience of 'fear' (see Figure One). In the model (Tudor, 2003, p. 247), depicts 'fear as a macro and a micro response, determined by everyday habitat, cultural practices and social structures on the one hand, and bodies, personalities and social subjects on the other'. Of these six 'analytical groupings' three are 'macroscopic and structuring in their emphasis 
(environments, cultures and social structures) [and] the second set are more focused on the contribution of individual agents (bodies, personalities and social subjects)' (Tudor, 2003, p. 247). Tudor proposes that the model should not be viewed as static, hierarchical but as relational and fluid with endless permutations between the six inextricably interlinked sub categories. Tudor emphasises this when he states of the diagrammatic representation that it is designed 'to avoid the temptation of reductionism - postulating one or another of the six parameters as dominant [...] Environments, cultures, social structures, bodies, personalities and social subjects are only analytically distinguishable. In a concrete situation, they will mutually modify each other's effects in the elaborate flow of social action (Tudor, 2003, p. 250).

At the macro level Tudor describes environments to mean both our physical environment (urban areas can be moulders of fear for example) and social environment. How we construct 'states of fearfulness' (Tudor, 2003, p. 249) in relation to the environment depends in part on 'cultures [which] are the reservoirs on which we draw to make our everyday lives make sense' and on social structures by which Tudor means social systems and social actors. At the micro level, Tudor explains '(bodies, personalities, social subjects) are more microscopic in emphasis, relating to agency rather than to structure. They provide the bases upon which we as social agents negotiate the terms of our fearfulness' (Tudor, 2003, p. 251). On this Tudor (2003, p. 251) says:

Our bodily, psychological and social characteristics impact upon the experience of fear, producing different individual responses to similar situations, or, indeed, individual consistency over time and space in response to different situations [...] active agents establish various modes in which they relate to their structuring 
environments, and in which that activity itself is grounded in bodily, psychological and social identity. Fear, then, is a product of interlocking relations between [...] structuring environments and the 'modes of individual fearfulness' derived from the individual.

Using this conceptual framework, this paper moves on to apply Tudor's ideas to qualitative findings gained from interviews with 26 residential child care workers in the Republic of Ireland regarding their experiences and views of relationship based practice within the residential child care sector.

\section{Research aims, objectives and methods}

The research concerns qualitative interviews with 26 residential childcare workers in the Republic of Ireland regarding their views of relationship based practice. This small-scale research study that took place in 2014 aimed to: explore residential childcare workers' understanding and views regarding this issue; to identify challenges and opportunities; and to contribute to debates regarding future practice. A purposive sample of residential childcare workers was recruited by contacting the relevant regional managers for residential child care facilities in their areas. Staff were made aware of the study and were then free to contact the researcher directly if they wished to participate. This way 26 workers were recruited to the study (see Table One). A qualitative methodology was adopted. Ethical approval was secured both by a university ethics committee and by the research governance teams of the different geographical areas then under the remit of the Health Service Executive in Ireland (this has since changed to an ethics committee under Tusla, only just being set up when the study was securing ethical approval). Confidentiality was constructed as conditional (if concerns about 
children's safety/wellbeing or poor practice emerged they would be reported to the relevant agencies in line with statutory requirements), consent was constructed as opt-in and ongoing, anonymity was guaranteed (through use of pseudonyms for participants and their geographical locations) and data collation and storage processes were clearly laid out and strictly adhered to. To safeguard the wellbeing of participants, the offer of a relevant counselling agency that could offer additional emotional support to staff post interview was made available.

Insert Table One about here

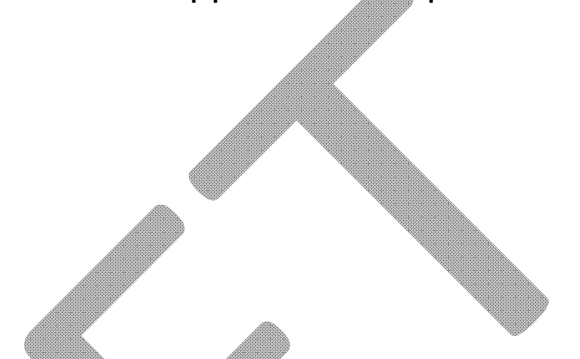

Qualitative interviews of varying lengths and in varying locations took place (see Table One) and were underpinned by an approach known as Appreciative Inquiry (AI). This is based on what is referred to as the 4-D cycle (Carter, 2006). The first phase is known as discovery (the best of what is or has been); the second as dreaming (what might be); the third as designing (what should be); and the fourth phase as destiny what will be (Carter, 2006). In the interview process the first two phases of 4-D cycle (discovery-dreaming) were focused on to help research participants open-up and engage in the interview process. A semi-structured interview schedule was used to guide thinking regarding relationship-based practice.

Data analysis involved a thematic approach involving four stages: immersion; coding; categorising and generation of themes (Braun and Clarke, 2006). Repeated reading and rereading of interview transcripts and field notes drew attention to tensions in the workers' accounts between aspirations regarding relationship based practice and the reality where relationship based practice in its broadest sense was constrained. In exploring these 
emergent themes, it became apparent that 'fear' provided a useful conceptual framework. In the final stage of the process, the construction of a thematic map underpinned by the broad conceptual framework of Furedi $(2005,2006)$ and Furedi and Bristow (2008) and further operationalised by the Tudor model (2003) allowed for reflection on the themes and any common links between them.

Before discussing the findings, it is important to acknowledge the limitations of the study. This was a small-scale study that involved 26 participants, all qualified residential child care workers with over 10 years of professional practice experience. The findings are limited first by the sample size. It is not possible to draw broad sweeping generalisations from a small dataset in which subjective, lived experience is the focus. It is only possible to draw out themes that are worthy of consideration and further follow up. Second, the accounts of the participants are largely retrospective and based on memory of past events. Memory and recall are selective and what is recalled is limited. That said, these limitations should not detract from the importance of lived experience or the themes that hitherto emerge and that are now reported on.

\section{Findings: the macro level, fear and experiences of residential child care workers}

\section{Environment}

Interviews revealed that with regards to the wider social environment, the position of residential child care in the Irish media as a set of institutions historically bringing fear and terror into the lives of hundreds of children (as noted earlier in the article), continues to have a direct impact on practice that is impossible to overstate. Notably, even after the 
establishment of new regulatory structures (Tusla, 2014), it is the perception of residential child care workers that the sector still lives in the shadow of the fear associated with it and that workers practice in this environment. One of the consequences is a denial of responsibility as noted in the interview excerpt with Breda:

You know we have come from a history where residential care I mean this week we have the nun laundry report and society was complicit completely in that and yet they want the nuns to take the rap for it now or whatever. So, society is complicit in [the failings of] residential care but how we deal with that is we pretend it doesn't exist.

The perception that, in the wider social environment, there is a denial of responsibility results in some residential child care workers feeling fearful that the sector remains cut off from wider reforms and feeds the perception that it is toxic and not worthy of investment. This is reflected in the words of one interviewee, Carrie who depicted herself as working in a sector that was at 'the end of the line'. Even though Health and Safety Executive was in period of transition during data collection (with the establishment of Tusla, 2014), there was no sense of anticipation or expectation from some workers that this new infrastructure would bring about meaningful change or investment, in fact for many participants they feared closure of units and appeared to cope by remaining disengaged from this change process.

\section{Social structures}

Combined with this, interviewees revealed some of the ways in which fear has become institutionalised in daily processes, practices and procedures of residential child care practice, 
what Tudor refers to as the social structures. The impact of this varied but one notable theme was the distancing of the broader organisation from its employees through strategies including, as highlighted by Furedi (2006), 'the individualisation' of blame for mistakes. For example, Annie a residential childcare worker, described her relationship with senior managers as 'distant, scattered and battered'. Further evidence of this relationship is described below:

I find it is because then there's investigations as it goes higher up, there's questions asked, there's emails from childcare managers, social workers are involved, there can be a lot of pointing fingers as to who's to blame for a decision made.

Mary, another residential childcare worker, explores these feelings further in the interview excerpt below:

Yeah [...] I don't know if litigation is the right word but it is, it is very much because so many people have been hurt and abused by the system. They are now making sure that a) it won't happen again and b) if it does and somebody does bring a case there are boxes of paperwork to back up yes, they have seen a doctor and yes, they have seen the dentist.

Further examples of the individualisation of practice failure are highlighted in the interview excerpts with June and Amber below. It is evident from the following excerpts that such management techniques cause feelings of vulnerability and fear. In the excerpt below a 
worker, June, notes how she was fearful of what she perceived to be the individualisation of practice failure:

If something major goes down it will be traced back to someone. In ways, no one ever takes the fall and in another way, you think they are looking for someone to take the fall.

This was further illustrated by Amber:

There can be a lot of pointing fingers as to who's to blame for a decision made if this basically goes pear shaped I'm the one, my neck is on the line'.

These views are indicative of a lack of trust in the senior management and perceptions have been informed by the organisation's response to historical institutional abuse inquiry reports, where several participants felt there had been no shared responsibility but rather a 'name and shame' type of approach in which individual 'workers were left were left out dry'. Hence the prevailing environment in which residential child care is designed and delivered and the social structures that shape processes and procedures in themselves give rise to a wider culture of fear that pervades the sector. The impact of this on workers is explored below.

\section{Cultures, fear and relationship based practice}

As outlined above, social structures can create a 'culture of fear' which shapes individual practice (here completion of paperwork). Tudor (2003) argues that culture provides the soil in which fearfulness may grow. In interviews with residential childcare workers, this was 
evidenced through their experiences and views of relationship based practice. While residential care workers aspire to build and nurture relationships with children in care, it was notable from interview transcripts that workers perceived all aspects of their relationships with children and young people to be hindered and hampered because of fear.

In trying to establish boundaries and routines, residential child care workers felt ill-equipped in their relationships with children and young people. Rose, for example, commented on how she felt she could no longer say 'no' to a young person stating that 'we now have find different ways of saying no' and that " no" is considered a bad word in residential care practice'. The overall impression was that if children and young people demanded access to resources and/or privileges these had to be acquiesced to, whatever the rights and wrongs, because the system was, in effect, frozen with its workers feeling unable to challenge young people and/or impose boundaries for fear of complaint.

With regards to the outward display of professionalism, residential child care workers felt that an 'objective', 'detached' persona was better regarded by senior management than an 'emotionally attuned and expressive' persona. There was a fear that the expression of emotion equated to 'over-involvement' and 'unprofessionalism'. In the interview excerpt below, for example, Annie expresses these themes:

I am conscious if I go to meetings if am too animated and too passionate and too you know then it's seen like 'Oh my god she is very involved'. 
Other residential childcare workers shared a similar view epitomised by Breda's experience where she reflected that her emotional investment was constructed as 'being in collusion' with the young person. Hence, it is within this context that in meetings residential childcare workers strived to present themselves as objective and detached for fear they would be considered unprofessional. Participants viewed professionalism as a detached and cold concept, evidenced by Tom who said that young people wanted someone 'that's good with children as opposed to someone then that's like a professional'. A similar theme was reflected in the words of Angie who felt that:

We're too professional in terms of the kids. But we need to be more professional with other professionals.

The cumulative impact of these cultural norms where emotion on the part of professionals was perceived as a bad created a sense of anxiety and fear regarding relationships and the development of risk-aversive practices. John, below describes their impact:

In the past often reading stories to children when in their beds: You know, one of them could be hanging over your shoulder and the other one would be just lying there. And you'd be just reading them a story. 99 out of 100 care workers wouldn't even put themselves in that position now.

Residential childcare workers discussed the growth of 'safe practice' which they equated with increased reliance on procedures and processes. Whilst residential childcare workers could reflect that this was supposed to lead to them 'feeling safer' it had the reverse effect in that 
reliance on a procedure led approach appeared, according to residential childcare workers, to reduce levels of self-confidence and the exercise of professional judgement in practice as indicated by Sally:

I'm a little disillusioned at the moment about it. It's nearly getting to the stage where you just get somebody and you give them a handbook, if a) happens you do b), if b) happens you do c) [and so on].

The perceived negative consequences of not adhering to procedural practice are outlined by Sally when she explains her fear that a more individual and creative type of practice might have meant that:

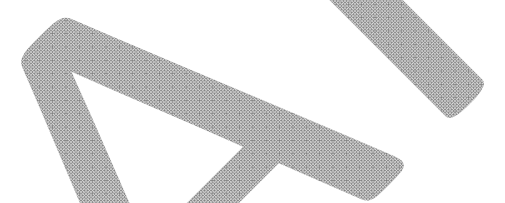

[...] management would have felt that it may have been seen in a way as grooming or that you were favouring them in some way and that you were bringing in personal things. It just took a bad turn so then you automatically you couldn't even bring in a book or lend them a book.

The impact on workers, children and young people of professionals following procedure rather than their own intuition is evidenced by in Annie's view below:

I am nearly almost working robotically whilst definitely each year I put less and less of myself into it. 
It is evident that from some of the findings of this group of residential child care workers that environmental and social structural factors have melded together to create culture of fear that impacts on daily practice. Just how these wider factors work at the level of daily practice is explored below using the micro level factors outlined in Tudor's framework and that include the analytical sub categories of social subjects, bodies and personalities.

\section{Micro level}

\section{Social subjects and barriers to agentic capacity}

Bearing in mind, Tudor's conception of agentic capacity (Tudor, 2003, p. 251) as outlined earlier in the article, the findings reported below illustrate that the mode of practice adopted by practitioners was to challenge prevailing structural discourses to engage in relationship based practice but in a context where challenges existed. The residential child care workers interviewed showed, as indicated above, an inherent anxiety related to the wider societal ambiguity regarding their role and identity. First, those interviewed drew attention to the limited understanding of the role of residential childcare workers by society at large and that any knowledge they did have was largely informed by negative media reporting. Workers highlighted a wide spread suspicion of relationship based practice, which was misconstrued as 'questionable and dubious'. June's comment exemplifies this:

People need to understand that we are not monsters; we want to do good by these children.

Second, workers described their professional status and position as at the 'bottom of the ladder' (Rose) and Mary as the 'sole of the shoe' and by John who stated: 
It's like the old saying, and they say, 'shit rolls down a hill', 'you know we're at the bottom.

Third, the emphasis on bureaucratic processes and procedures meant that workers described themselves 'very much trapped in paper work' (Amy). In another example, Rose described residential centres as 'the Big Brother house'. Rose also indicated that the existence of protocols could undermine worker confidence and discretion. Sally stated that:

Workers are being scrutinized in a very kind of clinical way and that they're being overly and harshly criticised for decisions that they've made, whereas for the past 10 years those decisions have been fine.

Although conscious of the barriers to establishing meaningful relationships with children and young people, in their interviews the residential childcare workers stressed the centrality of relationships defining them 'as crucial to a child's placement' (Annmarie).

They reflected backwards and drew upon nostalgic memories of past relationships, for example Mary said:

We had a real sense of ownership over, we'll say, the whole unit and the children in it, going to go to mass, not for a religious reason but because this was what we done and it's just good for them. 
While some workers were clear that engaging in meaningful relationships was less likely to happen today because of risk, fear and a managerial/surveillance culture, others highlighted their work (or the work of their colleagues) that challenged prevailing cultural, structural, organisational norms and provided (reflective of Tudor's framework) illustrative examples of agentic capacity. This theme is further explored below.

\section{Personalities}

On agentic capacity to challenge, through practice, prevailing norms, Tudor (2003: 250) states that 'some types of personality are given to anxiety: some are apparently fearless [...]. They are part of what is brought to bear in the application of agency in human activity'. In their own practice that often went against prevailing norms workers referred to relationship-based practice as comprising many skills and practices, the three most prominent being 'opportunity led practice', 'persistence' and 'genuine care' for young people. On the latter, John stated:

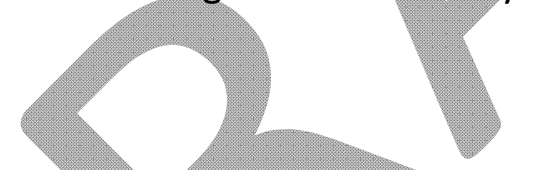

Young people are very aware; they've got radar! They know who genuinely cares, they know the staff members that genuinely care. They are very astute and they have good awareness of staff that care and ones that don't.

In the interview with Mary she spoke about how she communicated caring. Mary's practice focused on nurturing and demonstrating care as expressed through actions:

Even just the, eh, the, there's one little fella like he likes a mug of tea first thing in the morning. But it's having it done; you know having it kinda perfect, hot enough for him. 
Helen's description drew parallels with Mary's:

They're looking for a toasted sandwich or something. You know just the way; I'd even cut it up for them like I'd cut it up for my own children at home. You know in a nice, presented to them nicely. And maybe a few crisps or whatever on the side, something that you know they like.

These individual acts of care and of kindness paved the way for building of trust between the residential childcare workers and the young people. However, some staff pointed out that efforts to show genuine care are not experienced by young people as such because they lived in a context where this type of approach is not the norm.

Being present with a young person was viewed as creating pathways for conversations, it was when workers were 'just hanging out' or 'driving in the car' (Donna) that' they find that one little nugget', (John) 'that one twinkle of light' (Lara) or 'door openers' (Lucy). A further example of persistence and presence was described by Tom:

So, if, at a staff meeting, we say 'Well so and so has to be called on four occasions' [...] and then they can put it in a nice report saying 'I called so and so on four occasions' you know the staff member then has just gone through the motions [...] it's ticking all the boxes. But staff that really care will keep going back until the young person gets up for school, even though the young person is verbally abusive. That is caring for the young person. 
'Being yourself" was a term widely used by some of the residential childcare workers. This is an important word reflecting what Tudor referred to as personality and what also neatly captures the essence of agency to which Tudor (2003) refers. Within this context some residential childcare workers admitted maintaining their relationships with young people in 'their own time' but were fearful that this would viewed as unprofessional. Workers' positive relationships with young people had long term benefits for young people as depicted by Audrey:

Because I met one of the young lads one day and he said about going for a cup of coffee and I said, 'Sure come on sure I've an hour to spare, have you?' and he had. There's something lovely about it. Nobody needed to know how we knew each other and he was doing great.

\section{Bodies}

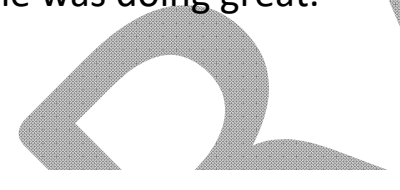

Particularly frustrating for a small number of those interviewed was the fact that these stories were unheard and were overshadowed by the legacy of past inquiries. For workers, this legacy tainted some of the most important elements of relationship based practice, namely those to do with touch - hugging, embracing, comforting for example. This theme of 'bodies' occupies an ambiguous role in residential child care. On one hand, touch/physicality in the form of restraint is condoned as occasionally necessary to protect children and young people against risks to themselves or others. However, on the other hand, other types of use of bodies/physicality (hugging a child or young person, holding their hand, brushing their hair, comforting them) are mentioned less often. An exception to this is the brief reference to 
residential childcare workers use of gestures/practice such as 'making tea as he likes it' rather than the use of language. It is suggested (although impossible to prove) that the lack of discussion about 'bodies' may be related to the fact that, in a context where the focus has been on the abuse of children and young people by workers in residential child care, gestures of care by workers that involve intimacy and touch may have been misconstrued as grooming and/or abuse and were avoided in conversation.

\section{Discussion, implications and concluding thoughts}

Reflecting on the findings, it appears that the experiences and views of residential child care workers regarding relationship-based practice have been compromised and constrained because of a prevailing 'culture of fear' that pervades the sector. In the context of the Irish residential childcare system, this is not surprising because fear as an emotion has been vividly depicted in the Inquiry reports and autobiographical accounts of adults who spent time in the care of the State as children (Ryan report, 2009; Touher, 1991; Tyrrell and Whelan, 2008. However, it is surprising to discover how far the culture of fear has shaped and informed the daily practice of the residential childcare workers interviewed in this study. From the findings are discussed three main themes, reflective of the work of Furedi $(2005 ; 2006)$ are discussed: construction of adults as 'predatory monsters'; individualisation of risk; and safe practice.

First, with regards to 'predatory monsters', Furedi (2006) has argued that the impact of misanthropy (the representation of all adults as a risk to children and young people) whilst invoking practices that set out to protect children and young people from risk has also operated to constrain and stifle expressions of warmth and affection that are fundamental aspects of human nature. From the findings, it is apparent that the residential child care 
workers interviewed, felt 'tainted' by this type of discourse to such an extent that it interrupted their ability to deliver core aspects of relationship based practice particularly around appropriate physical touch. Second, given of the prevailing discourse around the 'individualisation of risk', residential workers found it difficult to work in risk-enabling ways due to fear of blame or liability and fear of being held personally accountable (Furedi, 2006; Gharabaghi and Phelan, 2011; McPheat and Butler, 2014). Findings tend to support Furedi's (2007:71) point that fears can contribute to a climate where 'not taking risks is positively advocated', where risk-taking becomes viewed as irresponsible and accidents the result of risk management failings. Third, given the increased emphasis on 'safe practice', certain practices were favoured including the growth of record keeping. These all compromised the delivery of relationship based practice particularly, the intimate and relational aspects of their work with children including, for example, hugging and touching (Steckley, 2012; Soldevila et al., 2013).

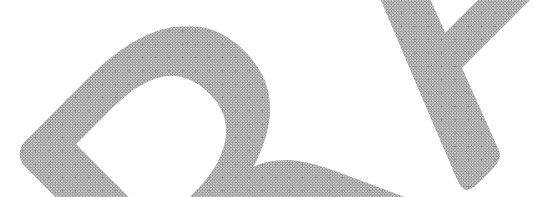

With these issues in mind, what are the implications of this study? These are best addressed by considering the findings in relation to policy development, service provision and professional practice. Regarding policy development, the ambiguous position occupied by the residential sector, where there has been a reluctant acknowledgement that the sector exists combined with overt attempts to place emphasis on alternative care provision, this has hindered the development of residential child care as a suitable, appropriate and preferred choice for some children and young people. The findings in this paper challenge policy developers to think again about the sector given the evidence of the care afforded by residential workers to children and young people and the ways in which children and young people respond positively to genuine acts of care offered in a safe environment. Rather than 
consign residential child care to the 'backwaters', a more productive policy response involves investing in models of residential child care practice that do have a positive impact. A reconfigured policy response, combined with a focus on assessing service provision in collaboration with children and young people could lead to change. These two structural responses must co-exist with investment in and commitment to the residential child care workforce. The lack of recognition of the elements that make up relationship-based practice at the micro level and that include the use of personality; the body; and use of self as a social subject, needs to be challenged and changed. This can only be achieved through creating space for dialogue with residential child care staff as their accounts of their experiences are central to any reform of their training, their approach in professional practice and their status. It is hoped that the findings from this small-scale study help contribute to efforts in this direction.

\section{References}

Anglin, J.P. (2014) Pain, Normality, and the Struggle for Congruence: Reinterpreting Residential Care for Children and Youth. Routledge, London.

Berridge, D., Biehal, N., Lutman, E., Henry, L. \& Palomares, M. (2011) Raising the Bar? Evaluation of the Social Pedagogy Pilot Programme in Residential Children's Homes. Department for Education Research Report, vol. DFE-RR148. Department for Education, London.

Braun, V. \& Clarke, V. (2006) Using thematic analysis in psychology. Qualitative Research in Psychology, 3(2), 77-101.

Cahill, O., Holt, S. \& Kirwan, G. (2016) Keyworking in residential child care: lessons from research. Children and Youth Services Review, 65, 216-223.

Carter, B. (2006) One expertise among many: Working appreciatively to make miracles instead of finding problems using appreciative inquiry as a way of reframing research. Journal of Research in Nursing, 11(1), 48-63.

Fenton, M. (2015) Social Care and Child Welfare in Ireland: Integrating Residential Care, Leaving Care and Aftercare. The Liffey Press, Dublin. 
Fulcher, L. (2001) Differential assessment of residential group care for children and young people. British Journal of Social Work, 31(3), 417-435.

Furedi, F. (2005) The Politics of Fear. Continuum, London.

Furedi, F. (2006) Culture of Fear Revisited. Continuum, London.

Furedi, F. \& Bristow, J. (2008) Licensed to hug: How Child Protection Policies are Poisoning the Relationship between the Generations and Damaging the Voluntary sector. Civitas, London.

Gallagher, B. \& Green, A. (2012) In, out and after care: young adults' views on their lives, as children, in a therapeutic residential establishment. Children and Youth Services Review, 34(2), 437-450.

Gharabaghi, K. \& Phelan, J. (2011) Beyond control: staff perceptions of accountability for children and youth in residential group care. Residential Treatment for Children and Youth, 28(1), 75-90.

Gilligan, R. (2009) Residential care in Ireland. In: Residential Care of Children: Comparative Perspectives, (eds. M. E. Courtney \& D. Iwaniec), pp. 3-19. Oxford University Press, Oxford.

Government of Ireland. (2009) Commission to Inquire into Child Abuse (CICA) (Vols I-V) (Ryan Report). The Stationary Office, Dublin.

Guardian newspaper (2017) (https://www.theguardian.com/world/2017/mar/03/massgrave-of-babies-and-children-found-at-tuam-orphanage-in-ireland)

Harder, A. T., Knorth, E. J. \& Kalverboer, M. E. (2013) A secure base? the adolescent-staff relationship in secure residential youth care. Child \& Family Social Work, 18(3), 305-317.

Kemshall, H. (2002) Risk, Social Policy and Welfare. Open University Press, Buckingham.

Macdonald, G., Millen, S., McCann, M., Roscoe, H. \& Ewart-Boyle, S. (2012) Therapeutic Approaches to Social Work in Residential Child Care Settings. Social Care Institute for Excellence, Belfast.

McPheat, G. \& Butler, L. (2014) Residential child care agencies as learning organisations: Innovation and learning from mistakes. Social Work Education, 33(2), 240-253.

Raftery, M. and O'Sullivan, E. (1999) Suffer the Little Children: The Inside Story of Ireland's industrial schools. New Island Books, Dublin.

Ruch, G., Turney, D. \& Ward, A. (eds.) (2010) Relationship-Based Social Work: Getting to the Heart of Practice. Jessica Kingsley Publishers, London.

Saldaña, J. (2009) The Coding Manual for Qualitative Researchers. Sage, Thousand Oaks, CA.

Smith, M. (2009) Re-thinking Residential Child Care: Positive Perspectives. Policy Press, Bristol. 
Soenen, B., D'Oosterlinck, F. \& Broekaert, E. (2013) The voice of troubled youth: children's and adolescents' ideas on helpful elements of care. Children and Youth Services Review, 35(9), 1297-1304.

Steckley, L. (2012) Touch, physical restraint and therapeutic containment in residential child care. British Journal of Social Work, 42(3), 537-555.

Touher, P. (1991) Fear of the Collar: Artane Industrial School. O'Brien Press, Dublin.

Tudor, A. (2003) A (macro) sociology of fear? Sociological Review 81(2), 238-256.

Tyrrell, P. \& Whelan, D. (2008) Founded on Fear. Transworld Ireland, Dublin.

Whittaker, J., Valle, J. \& Holmes, L. (eds.) (2015) Therapeutic Residential Care for Children and Youth. Jessica Kingsley Publishers, London.

Williams, D. \& Lalor, K. (2001) Obstacles to the professionalisation of residential child care in Ireland. Irish Journal of Applied Social Studies, 2(3), 73-90. 
Table 1. Full Study Participants

\begin{tabular}{|c|c|c|c|}
\hline Gender & $\begin{array}{c}\text { Location of Residential } \\
\text { Centre }\end{array}$ & Interview Location & $\begin{array}{l}\text { Duration } \\
\text { (minutes) }\end{array}$ \\
\hline $\mathrm{F}$ & Mid-Leinster & AIT. & 47 \\
\hline $\mathrm{F}$ & Mid -Leinster & AIT. & 48 \\
\hline $\mathrm{F}$ & Mid -Leinster & AIT & 49 \\
\hline $\mathrm{F}$ & Mid -Leinster & AIT & 42 \\
\hline $\mathrm{F}$ & Mid- Leinster & Hotel & 53 \\
\hline $\mathrm{F}$ & Mid -Leinster & AIT & 43 \\
\hline $\mathrm{F}$ & Mid- Leinster & Hotel & 65 \\
\hline$M$ & Dublin-Region & Hotel & 78 \\
\hline $\mathrm{F}$ & Dublin-Region & Residential Centre & 75 \\
\hline $\mathrm{F}$ & South-East & Residential Centre & 46 \\
\hline$M$ & Dublin-Region & Family Resource Centre & 68 \\
\hline $\mathrm{F}$ & Dublin-Region & Family Resource Centre & 64 \\
\hline $\mathrm{F}$ & Dublin-Region & Family Resource Centre & 49 \\
\hline $\mathrm{F}$ & Dublin Region & Family Resource Centre & 65 \\
\hline $\mathrm{F}$ & Sout & Residential Centre & 62 \\
\hline $\mathrm{F}$ & Sol & Residential Centre & 52 \\
\hline M & Sout & Residential Centre & 66 \\
\hline $\mathrm{F}$ & South & Residential Centre & 44 \\
\hline$F$ & South & Residential Centre & 50 \\
\hline$F$ & South & Residential Centre & 63 \\
\hline$F$ & South-East & Residential Centre & 54 \\
\hline $\mathrm{F}$ & South-East & Residential Centre & 52 \\
\hline $\mathrm{F}$ & South-East & Residential Centre & 54 \\
\hline$F$ & Mid-Leinster & Residential Centre & 59 \\
\hline M & Mid-Leinster & Residential Centre & 66 \\
\hline $\mathrm{F}$ & Mid-Leinster & Residential Centre & 47 \\
\hline
\end{tabular}


Figure One: Sociological framework for fear - adapted from Tudor 2003

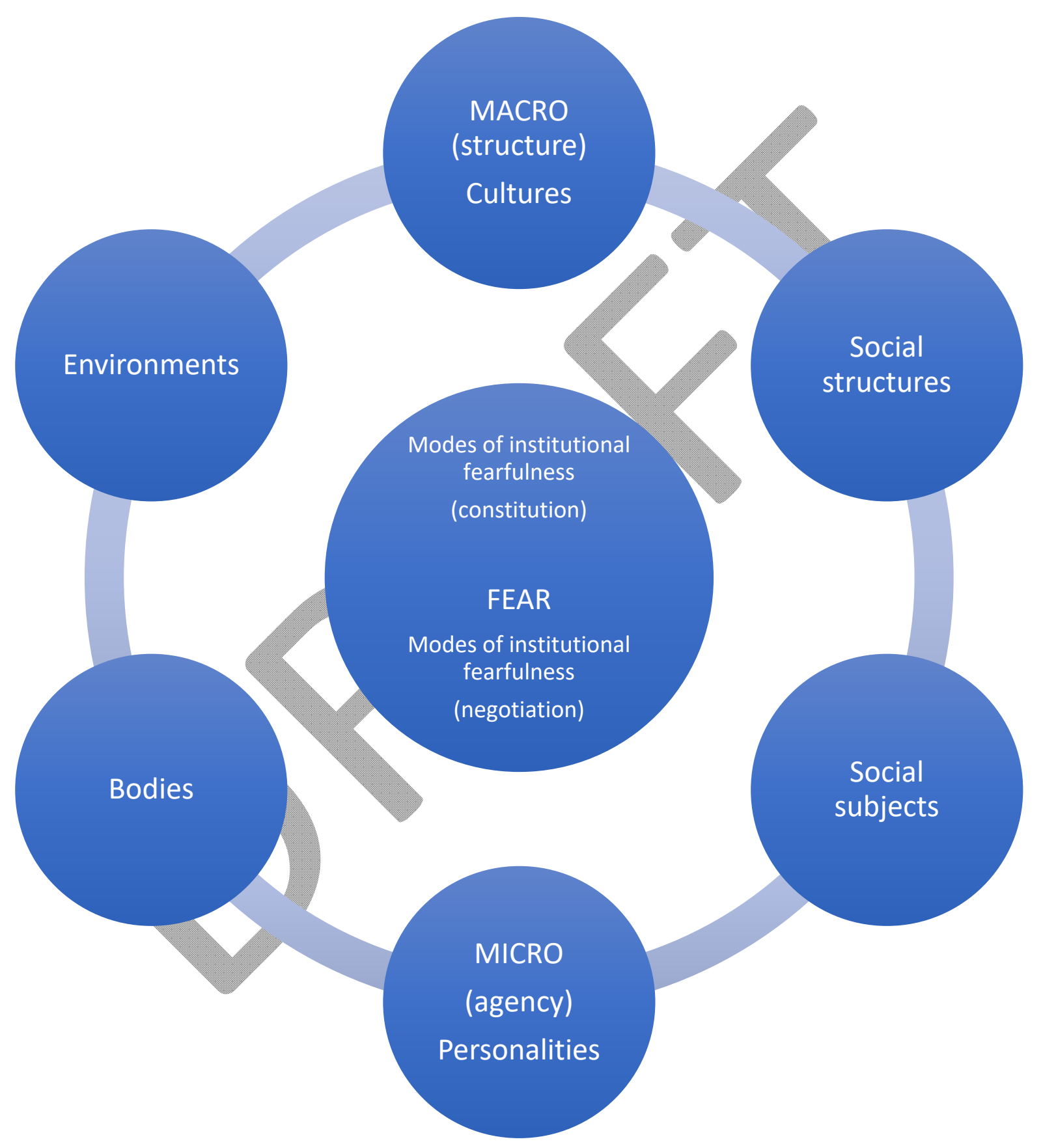

